\title{
A histological and biomechanical study of bone stress and bone remodeling around immediately loaded implants
}

\author{
HAN Jing Yun ${ }^{1}$, HOU JianXia ${ }^{2}$, ZHOU Gang ${ }^{1}$, WANG Chao ${ }^{1} \&$ FAN YuBo ${ }^{1 *}$ \\ ${ }^{1}$ Key Lab for Biomechanics and Mechanobiology of Ministry of Education, School of Biological and Medical Engineering, Beihang University, \\ Beijing 100191, China; \\ ${ }^{2}$ Peking University School and Hospital of Stomatology, Beijing 100081, China
}

Received August 29, 2013; accepted November 25, 2013; published online May 12, 2014

\begin{abstract}
Immediate loading (IL) increases the risk of marginal bone loss. The present study investigated the biomechanical response of peri-implant bone in rabbits after IL, aiming at optimizing load management. Ninety-six implants were installed bilaterally into femurs of 48 rabbits. Test implants on the left side created the maximal initial stress of 6.9 and $13.4 \mathrm{MPa}$ in peri-implant bone and unloaded implants on the contralateral side were controls. Bone morphology and bone-implant interface strength were measured with histological examination and push-out testing during a 12-week observation period. Additionally, the animal data were incorporated into finite element (FE) models to calculate the bone stress distribution at different levels of osseointegration. Results showed that the stress was concentrated in the bone margin and the bone stress gradually decreased as osseointegration proceeded. A stress of about 2.0 MPa in peri-implant bone had a positive effect on new bone formation, osseointegration and bone-implant interface strength. Bone loss was observed in some specimens with stress exceeding 4.0 MPa. Data indicate that IL significantly increases bone stress during the early postoperative period, but the load-bearing capacity of peri-implant bone increases rapidly with an increase of bone-implant contact. Favorable bone responses may be continually promoted when the stress in peri-implant bone is maintained at a definite level. Accordingly, the progressive loading mode is recommended for IL implants.
\end{abstract}

implant, osseointegration, bone remodeling, immediate loading, finite element analysis

Citation: Han JY, Hou JX, Zhou G, Wang C, Fan YB. A histological and biomechanical study of bone stress and bone remodeling around immediately loaded implants. Sci China Life Sci, 2014, 57: 618-626, doi: 10.1007/s11427-014-4657-7

Endosseous implants have been extensively used in orthopedic, maxillofacial and oral surgery for replacements of lost or partially damaged hard tissues [1]. Currently IL is an emerging treatment alternative that may be described functional loading immediately after implantation without waiting for healing period [2-4]. In contrast, the conventional protocol advocates a two-stage technique with a load-free and at least 3-6 months healing. Apparently, IL increases implant acceptability by reducing treatment time and providing both physical and psychological benefits to pa-

*Corresponding author (email: yubofan@buaa.edu.cn) tients [5]. However, IL increases the risk of overloadinduced bone loss that can affect the soft tissue aesthetics and may cause implant loosening or loss [6-10] compared with conventional implant protocols $[11,12]$.

Accordingly, a study on the biomechanical bone response surrounding IL implants is necessary for understanding the osseointegration process after IL, and therefore can provide the theoretical basis for optimizing load management and improving implant design. Animal experiments have been conducted to address that, but results remain controversial $[13,14]$. This is because mechanical environment and biological reactions of peri-implant bone are 
complex. First, different levels of osseointegration can directly affect bone stress magnitude and distribution, and a change in bone stress can alter the bone turnover and remodeling activity [15-17]. Second, mechanical stimulation sensed by peri-implant bone is different due to unique implant designs, bone quality and implant surface topography even with identical loading. Third, the stress change in peri-implant bone cannot be measured in vivo by existing experimental techniques. Compared with animal model limitations, FE analysis is an effective tool for studying the stress distribution in the peri-implant bone [18-20]. However, most related FE literature assumed a frictional contact between implant and bone and only evaluated IL on initial stress distribution in peri-implant bone [21,22]. Additionally, although some FE models simulated bone stress distribution during the osseointegration process, these models have not been related to in vivo data [23-27]. Thus, little is known about the bone stress and subsequent bone response after IL.

In view of this, the purpose of this study was to comprehensively investigate the interaction between IL-induced bone stress and peri-implant bone response in a rabbit model.

\section{Materials and methods}

\subsection{Implant design, loading protocol and surgical pro- cedure}

A turned implant (Figure 1A) and a loading device (Figure 1B) consisting of the gasket, retaining cap and compression spring, were designed. The upper part of the implant had a tapered surface with a maximum diameter of $2.8 \mathrm{~mm}$ and length of $15 \mathrm{~mm}$, and the lower part was a screw-shaped cylinder which was used to assemble with the internal thread of the retaining cap. The spring was compressed in the enclosed space between the gasket and retaining cap and its reaction force was transmitted to the implant by the retaining cap. Because of the complexity of the mechanical environment in the bone tissue adjacent to the gasket (Figure $1 \mathrm{~B}$, side $\mathrm{B}$ ), only the peri-implant bone (side A) was used for the biomechanical analyses. A $500 \mu \mathrm{m}$-wide zone around the implant at this side was defined as the region of interest (ROI).

Forty-eight nine-month-old male New Zealand skeletally mature white rabbits (mean $3.7 \mathrm{~kg}$ ) were used and $96 \mathrm{im}$ plants were installed bilaterally into the femurs. General anesthesia was induced via ear vein injection $\left(30 \mathrm{mg} \mathrm{kg}^{-1}\right.$ pentobarbital). Local anaesthesia $(2.0 \mathrm{~mL} 2 \%$ lidocaine $)$ was applied after the hind legs were shaved and cleaned. Femurs were exposed by two medial and lateral longitudinal incisions $(15 \mathrm{~mm})$. Then, a round hole $(1.5 \mathrm{~mm}$ in diameter $)$ was drilled and a subsequent conical hole was drilled in the femur $15 \mathrm{~mm}$ distal to femoral metaphysis with irrigation. Rabbits were grouped randomly, and the test implants with loading devices (5 or $10 \mathrm{~N}$ loads) were installed on the left sides (Figure 2). Unloaded implants on the contralateral sides were controls. Postoperatively, animals received antibiotics (penicillin, $400000 \mathrm{U} \mathrm{d}^{-1}$ ) for $5 \mathrm{~d}$ to prevent infection. The experimental protocol was approved by the Medical Ethical Committee for Animal Investigations of Peking University Health Science Center in Beijing, China.

\subsection{Histological and histomorphometric evaluation}

Twelve animals were sacrificed at every observation time point (4th, 8th and 12th postoperative weeks) and six samples in each group were obtained to evaluate histological and histomorphometric changes in peri-implant bone. To prepare ground sections, femurs containing implants were fixed in $10 \%$ buffered formalin and then dehydrated in an ascending alcohol gradient. Subsequently, specimens embedded in methymethacrylate without decalcification and all sections were cut parallel to the loading direction in the middle of implants using a rotary diamond saw (SP1600, Leica, Germany). Finally, one section per implant was ground and polished to a final thickness of $30 \mu \mathrm{m}$ with a

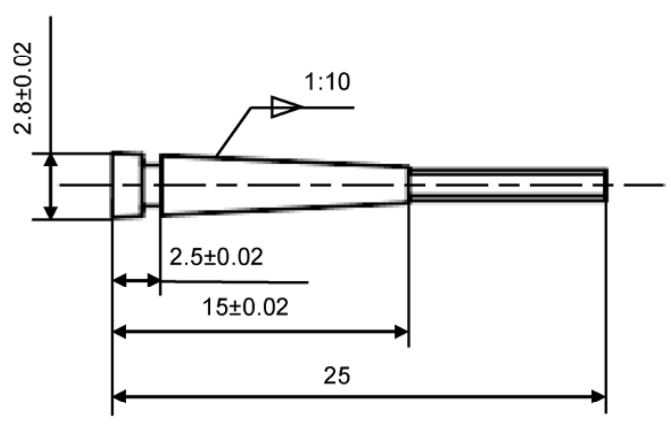

A

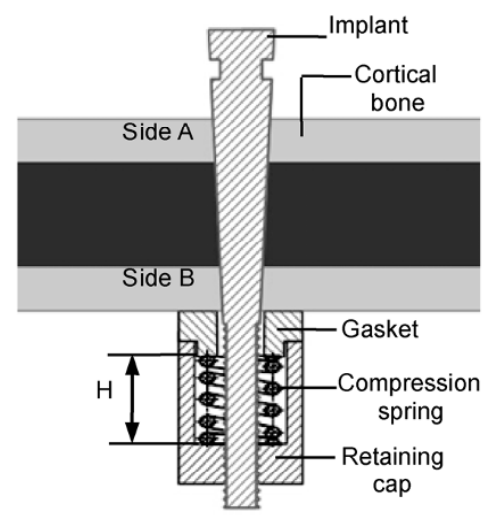

B

Figure 1 The assembly of the implant, loading device and rabbit femur. 


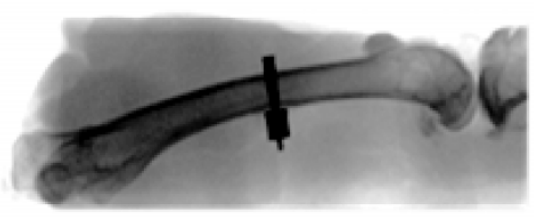

Figure 2 A fluoroscopy image of the rabbit femur with the implant and loading device.

grinding system (ExaktApparatebau, Norderstedt, Germany) and stained with methylene blue-basic fuchsin.

Light microscopy at $250 \times$ magnification was used for histological evaluation to evaluate bone morphological changes during the osseointegration process. The bone-toimplant contact ratio (BIC\%: total length of bone contact to total length of the implant interface in the cortical bone) and bone volume ratio (BV\%: total area of bone in ROI to total ROI area) were measured using a computer-assisted imaging system (Image-Pro Plus; Leica, Mikrosysteme Vertriebs, Bensheim, Germany).

\subsection{Finite element analysis}

Rabbits were scanned with micro-CT and femurs and implants were reconstructed. The loading device was simplified to a cylindrical base with an inner hole (Figure 3 ). The peri-implant bone and the base were meshed with a 20-node hexahedron element and the remaining geometric models were meshed with a 10-node tetrahedron element. The total elements and nodes were 54733 and 64961 respectively. All materials used in the FE analyses were isotropic, homogeneous and linearly elastic. Young's modulus (E) and Poisson's ratio $(\mu)$ of pure titanium (implant and base) and rabbit femur were $105 \mathrm{GPa} / 0.33[28,29]$ and $10 \mathrm{GPa} / 0.32$ [30,31], respectively. The static load of 5 and $10 \mathrm{~N}$ was applied axially to the bottom surface of the implant. All nodes at the bottom of the cylindrical base were treated as a fixed boundary. The mesial and distal borders of the femur were constrained in all degrees of freedom except the Z-direction.

Two different contact types, i.e., "frictional contact" and "bonded contact", were defined at the implant-bone interface. For frictional contact that indicated a nonintegrated state, frictional sliding was allowed between the smooth-turned implant and the peri-implant bone and the frictional coefficient was 0.3 [32]. The "bonded contact" meant an integrated state, so sliding and separation at the implant-bone interface was not allowed. We constructed five models with different $\mathrm{BIC} \%(0,25 \%, 50 \%, 75 \%$ and $100 \%)$. The integrated and non-integrated areas were alternated along the bone-implant interface. In addition, BIC $\%$ from experimental measurements was incorporated into $\mathrm{FE}$ models and bone stress distribution was simulated. All calculations in this study were accomplished in the commercial software ABAQUS 6.9 (Abaqus Inc., Providence, RI, USA).

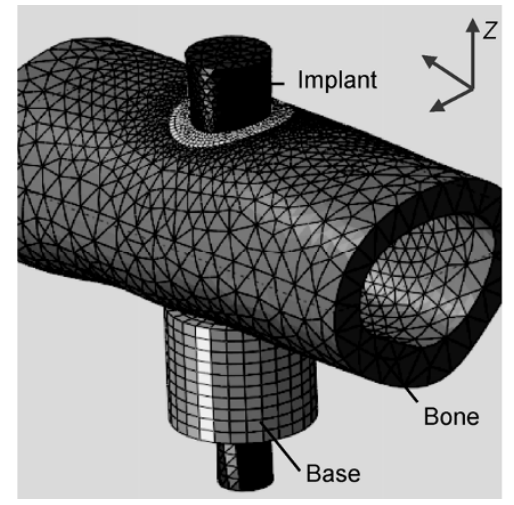

Figure 3 3D FE model of the rabbit femur with an implant.

\subsection{Biomechanical testing}

At the 12th postoperative week, remaining animals were sacrificed for push-out testing. Bone segments with implants were then removed from the adjacent tissue. To ensure that push-out force was transferred only to the bone tissue at side A, a slot around the gasket was cut using a diamond disk (Figure 4). Then segments were partially immersed parallel to the implant axis in a small rectangular container that was filled with polymethylmethacrylate (PMMA). After PMMA solidification, the specimen was firmly seated on a material machine (AG-IS, Shimadzu, Japan) with a clamp and push-out testing was performed at a constant displacement rate of $1.0 \mathrm{~mm} \mathrm{~min}^{-1}$. Finally peak push-out forces were monitored, and interfacial shear strength was calculated.

\subsection{Statistical analysis}

Quantitative analyses of histomorphometric examination and push-out testing are given as mean \pm standard deviations (SD). The significance of difference between controls and

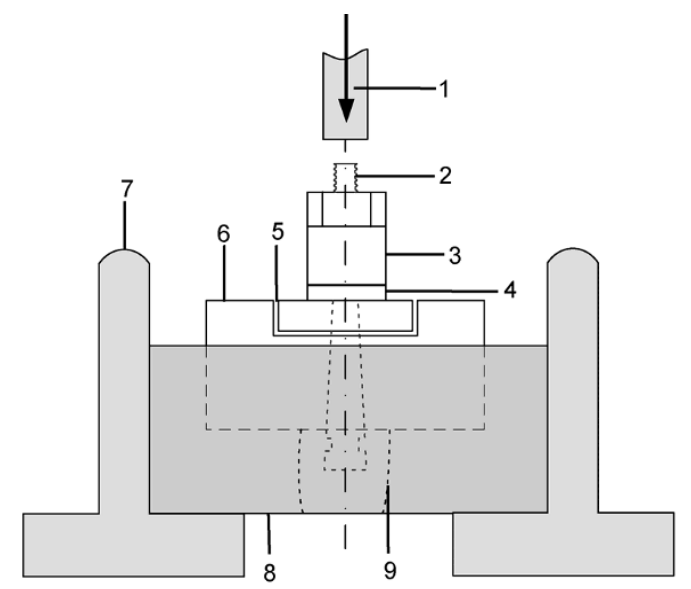

Figure 4 Experiment setup of push-out testing. 1, loading rod; 2, implant; 3 , retaining cap; 4, gasket; 5, slot; 6, femur; 7, clamp; 8, PMMA; 9, plasticine. 
test groups was assessed with the help of SPSS 13.0 (SPSS Inc, 13.0 for Windows, Chicago, IL, USA) and an independent sample $T$-test was performed ( $P>0.05$ was a threshold for statistical significance.).

\section{Results}

\subsection{Stress in peri-implant bone and displacement of implants}

Bone stress distribution was approximately the same for both types of loaded models. Figure 5 depicts comparisons of stress plots in peri-implant bone at different osseointegration levels. We observed that the stress concentrated on the outer marginal bone. As osseointegration progressed, bone stress gradually decreased and the stress difference was weakened between the outer and inner marginal bone. A trend was observed: the greater the $\mathrm{BIC} \%$, the more homogeneous the bone stress and the lower the bone stress magnitude.

Table 1 depicts peak von-Mises stress in the peri-implant bone $\left(\sigma_{\max }^{\mathrm{b}}\right)$ and displacement in the implant $\left(s_{\max }^{\mathrm{i}}\right)$ which was greatest at stage I. When BIC $\%$ increased, $\sigma_{\max }^{\mathrm{b}}$ and $s_{\max }^{\mathrm{i}}$ gradually decreased. A marked decrease occurred from stage I to III, and $\sigma_{\max }^{\mathrm{b}}$ and $s_{\max }^{\mathrm{i}}$ were higher at the integrated nodes than the adjacent nonintegrated nodes on the bone-implant interface.
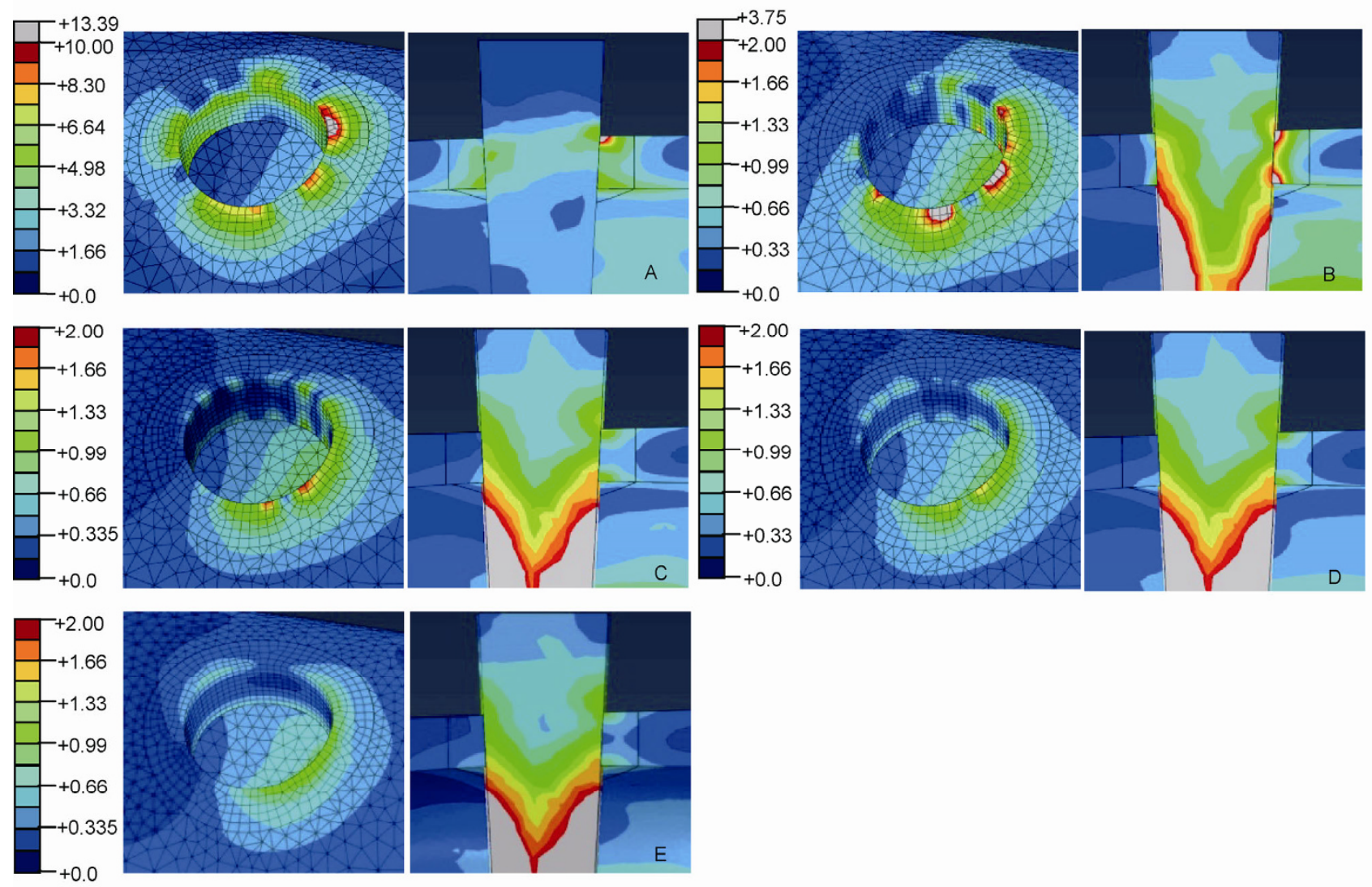

Figure 5 von-Mises stress distribution in peri-implant bone at different osseointegration levels. BIC\%: A, 0; B, 25\%; C, 50\%; D, 75\%; E, 100\%.

Table 1 Maximum von-Mises stresses of peri-implant bone and the displacement of implants at different osseointegration levels ${ }^{\text {a) }}$

\begin{tabular}{|c|c|c|c|c|c|c|}
\hline \multirow{3}{*}{$\mathrm{BIC} \%$} & \multicolumn{2}{|c|}{$5 \mathrm{~N}$-loaded model } & \multirow{3}{*}{$s_{\max }^{\mathrm{i}}(\mathrm{mm})$} & \multicolumn{2}{|c|}{$10 \mathrm{~N}$-loaded model } & \multirow{3}{*}{$s_{\max }^{\mathrm{i}}(\mathrm{mm})$} \\
\hline & $\sigma_{\max }^{\mathrm{b}}(\mathrm{MPa})$ & $\sigma_{\max }^{\mathrm{b}}(\mathrm{MPa})$ & & $\sigma_{\max }^{\mathrm{b}}(\mathrm{MPa})$ & $\sigma_{\max }^{\mathrm{b}}(\mathrm{MPa})$ & \\
\hline & $\mathrm{OMB}$ & IMB & & $\mathrm{OMB}$ & IMB & \\
\hline 0 , Stage-I & 6.93 & 3.04 & $8.78 \times 10^{-3}$ & 13.39 & 6.07 & $1.60 \times 10^{-2}$ \\
\hline $25 \%$, Stage-II & 1.83 & 1.68 & $2.42 \times 10^{-3}$ & 3.75 & 3.45 & $4.87 \times 10^{-3}$ \\
\hline $50 \%$, Stage-III & 0.93 & 0.84 & $2.03 \times 10^{-3}$ & 1.94 & 1.71 & $4.15 \times 10^{-3}$ \\
\hline $75 \%$, Stage-IV & 0.74 & 0.66 & $1.92 \times 10^{-3}$ & 1.54 & 1.39 & $3.88 \times 10^{-3}$ \\
\hline $100 \%$, Stage-V & 0.54 & 0.49 & $1.79 \times 10^{-3}$ & 1.12 & 1.02 & $3.64 \times 10^{-3}$ \\
\hline
\end{tabular}

a) OMB, outer marginal bone; IMB, inner marginal bone. 


\subsection{Histomorphometric analysis and bone stress at observation time points}

BV\% varied from $66.7 \%$ to $82.9 \%$ in ROI (Figure $6 \mathrm{~A}$ ). At the 4th week, BV\% in group A $(5 \mathrm{~N})$ was significantly higher than that in controls $(P=0.033)$, but no significant difference was observed between controls and group B $(10 \mathrm{~N})$. Over the next eight weeks, BV\% changed little in group A, while BV\% in group B rapidly increased and exceeded that in the other two groups. Especially at the 12th week, BV\% in group B significantly increased when compared with controls $(P=0.018)$.

Figure $6 \mathrm{~B}$ presents $\mathrm{BIC} \%$ at different observation time points. At the 4th postoperative week, BIC\% of group B was lowest, and this significantly improved at the next two observation points $(P=0.051$ and $P=0.001$ respectively). At the 12th week, BIC\% increased to $46.31 \%$ and was higher than that of controls and group A $(P=0.050$ and $P=0.183$ respectively).

Peak von-Mises stress of the peri-implant bone in the two loaded groups at the 4th, 8th, and 12th postoperative week is depicted in Table 2 .

\subsection{Histological evaluation}

Four weeks after implantation, the bone remodeling around implants was active, and abundant osteoids and woven bone were created. Clear cement lines of demarcation were apparent between the new bone and original resorbed surface. Compared with controls (Figure 7A), group A (Figure 7B) had more newly formed bone, especially in the outer bone region adjacent to the periosteum. Histological features of group B (Figure 7C) were similar to controls.

In the next eight weeks, complete bone remodeling around implant had occurred and the newly formed bone

Table 2 Maximum von-Mises stresses of the peri-implant at different observation time points

\begin{tabular}{cccccc}
\hline \multirow{2}{*}{$\begin{array}{c}\text { Observation } \\
\text { time points }\end{array}$} & \multicolumn{2}{c}{5 N-loaded group (MPa) } & & \multicolumn{2}{c}{ 10 N-loaded group (MPa) } \\
\cline { 2 - 3 } \cline { 5 - 6 } 4th week & OMB & IMB & & OMB & IMB \\
\hline 8th week & 1.87 & 1.12 & & 4.01 & 2.43 \\
12th week & 1.10 & 1.02 & & 2.37 & 2.17 \\
\hline
\end{tabular}

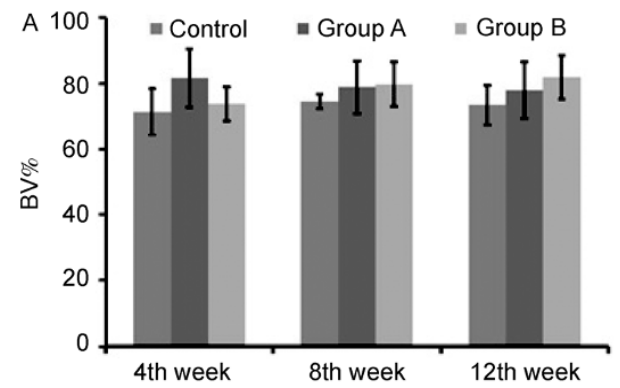

continued to increase. The area of the second bone contact significantly increased with the disappearance of the primary contact compared with that at the 4 th postoperative week. The two types of load applied to the implants were positive for bone healing and osseointegration. Newly formed bone and the osseointegration percentage in the marginal bone region adjacent to the endosteum in group B were significantly greater than controls and groups A. However, slight bone loss at the outer bone margin was observed in some specimens of group B at the 8th and 12th postoperative weeks. In addition, some woven bone around the implants in group B matured into lamellar bone at the 12th week.

\subsection{Bone-implant interface strength}

Table 3 shows the biomechanical data obtained from the push-out testing. The maximum force and the maximum interface strength occurred in group B. Compared with controls, the shear strength at the bone-implant interface significantly increased in groups A and B at 12th postoperative week ( $P=0.004$ and $P=0$, respectively).

\section{Discussion}

Overload-induced bone loss is a common problem after IL. Previous reports indicate that bone cells can respond to mechanical stimuli [33-37]. X-ray imaging, computerized tomography, resonance frequency and histomorphometric evaluation have documented the positive or negative effect [37-39] of external force on bone response, but the real stress environment in peri-implant bone and the subsequence bone response have not been adequately explained

Table 3 Bone-implant interface strength in the control and experimental groups

\begin{tabular}{ccc}
\hline Group & $\begin{array}{c}\text { Maximum force } \\
(\mathrm{N})\end{array}$ & $\begin{array}{c}\text { Interface strength } \\
(\mathrm{MPa})\end{array}$ \\
\hline Control & 12.54 & $11.46 \pm 0.75$ \\
A & 18.60 & $15.32 \pm 1.80$ \\
B & 19.02 & $17.37 \pm 1.27$ \\
\hline
\end{tabular}

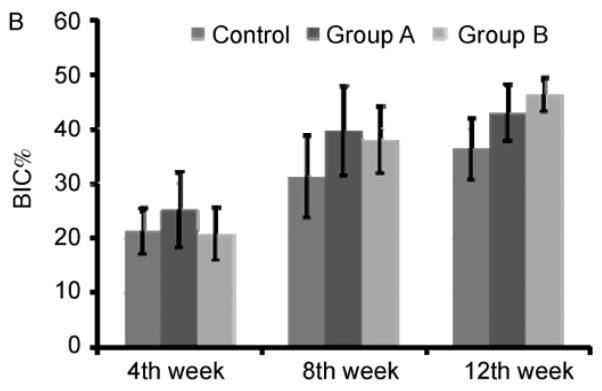

Figure $6 \mathrm{BV} \%$ and $\mathrm{BIC} \%$ at the observation time points. 

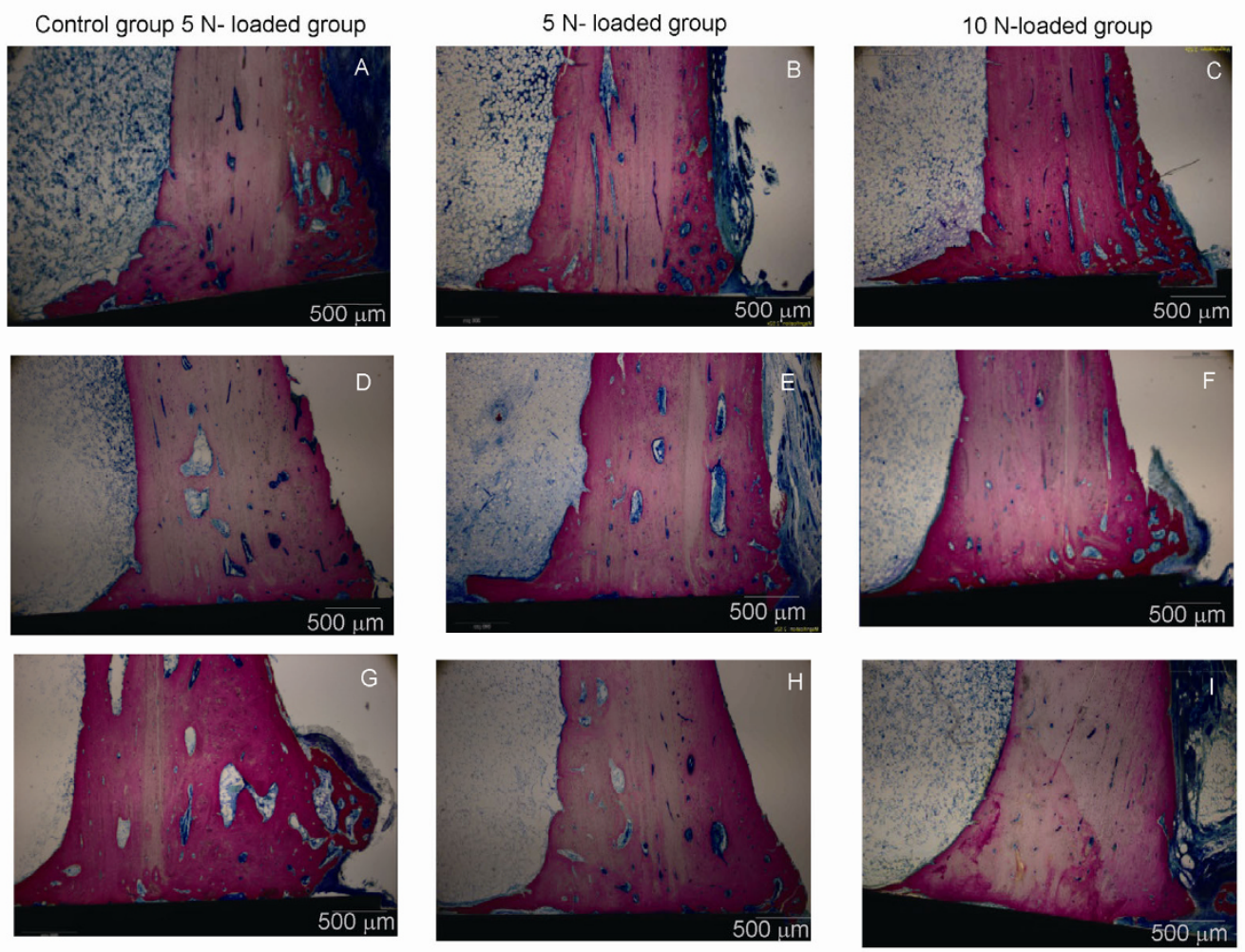

Figure 7 Histological sections of femurs with implants (methylene blue-basic fuchsin stain, original magnification $250 \times$ ). The 4 th week (A-C), the 8th week $(\mathrm{D}-\mathrm{F})$ and 12 th week $(\mathrm{G}-\mathrm{I})$.

during the osseointegration process, due to in vivo measurement limitations. Therefore, we used rabbit model with corresponding FE analysis to evaluate the effect of bone stress on bone remodeling around IL implants.

In order to minimize the effect of bioactive coating [40,41] and roughness [42] in animal experiments and to simplify quantitative descriptions about physiological characteristics of bone-implant interface in FE models, turned pure titanium implants were used. Compared with surface-modified implants, turned implants take longer to form new bone and bone-implant integration. According to Roberts and co-worker [43], mammals and humans have similar biological responses to mechanical stimuli and the cortical bone of rabbits remodels three times faster than human cortical bone. Thus the experimental period of 12 weeks in rabbit would correspond to 36 weeks in human body. Additionally, in the application of FE method to study orthopedic biomechanics, there exists a disadvantage that it is difficult to obtain precise stress distribution due to the lack of real material properties and the nonlinear complexities. In this study, we assumed that the femur was homogenous and linearly isotropic. The assumption may influence the accuracy and applicability of the results. However, the models did have advantages over published FE models [44,45]. First, the models were built on the real bone sample, and the experimental measurements of $\mathrm{BIC} \%$ were incorporated into FE models to simulate real situation of specimen events.
Second, the peri-implant bone was meshed with small hexahedron elements (averaging $0.15 \mathrm{~mm}$ ) to prove the calculation accuracy and reflect the difference of BIC\%.

The biomechanical response of peri-implant bone was related with loading time. Some research has focused on the bone response to the static delayed load, but knowledge about the effect of immediate static loading is limited. Our data indicate that IL could significantly affect the stress magnitude and distribution pattern in peri-implant bone. During the postoperative early period, BIC\% was relatively low and the stress distribution in peri-implant bone was not uniform under IL. High stress was mainly concentrated in the bone margin, and the outer marginal bone stress was always greater than the inner marginal bone stress during the osseointegration process. Therefore, the bone resorption is more likely to appear at the outer bone margin. These data agree with precious studies $[25,46,47]$. Meanwhile, we observed that bone stress decreased and its distribution tended to be more uniform as $\mathrm{BIC} \%$ increased. A rapid reduction in bone stress before $\mathrm{BIC} \%$ grew to $50 \%$ occurred, suggesting that the load-bearing capacity of the bone tissue around implants was weak during the postoperative primary period compared with the fully integrated implants. Thus, immediate or early functional load can increase stress in the peri-implant bone. This result can explain why IL has a greater risk of overload than conventional implant protocols. Accordingly, progressive loading should be better for post- 
operative bone remodeling and bone-implant integration compared to constant loading during the healing period.

FE analysis and animal experiments showed that the bone response changed along with changes in bone stress. At the 4th week, histological and morphometric evaluation of group A was better than that of controls and group B, and higher $\mathrm{BIC} \%$ and $\mathrm{BV} \%$ in the high stress region (i.e., the outer marginal bone of group A) where the maximum von-Mises stress was about 2.0 $\mathrm{MPa}$. In the next eight weeks, bone stress in group A rapidly reduced to about 1.0 $\mathrm{MPa}$. This bone response apparently weakened and no significant difference was found when compared with controls. Group B had the most energetic bone remodeling and osseointegration during this period, and newly formed bone and osseointegartion from the 8 th to the 12 th week were significantly higher than the other two groups in the inner marginal bone where the maximum von-Mises stress was about 2.0 MPa. Bone loss was observed in some specimens of group $\mathrm{B}$, which may have been reduced by the high stress of the outer bone margin during the first four weeks after the operation. In addition, the loaded implants had stronger anchorage in push-out testing. The data suggest that the activity of bone remodeling and osseointegration around implants is related to bone stress. Too much or too little bone stress cannot effectively promote a bone response. These data support the theory of 'bone's mechanical usage window' by Frost's group [33,48]. Meanwhile, within limitations of this study, the stress environment of $2.0 \mathrm{MPa}$ in peri-implant bone was conducive to bone remodeling. Thus, we suggest that the favorable bone response can be continually promoted when the bone stress magnitude is maintained at this level.

IL has diverse patterns due to difference in implant protocols. In a rabbit experiment, Halldin and colleagues designed the interference fit between the support bone and implants [49] and investigated the effect of predetermined static loading on bone remodeling. They found that bone resorption did not occur although the initial bone strain exceeded its yield strain and even the bone ultimate strain. In contrast, bone stress much smaller than bone yield stress caused bone loss in our study. Such difference may indicate bone tissue around implants has greater endurance to original loading than later functional or non-functional loading. In addition, Halldin's group observed that there was no significant difference between the two test groups with different initial bone strain. Conversely, the test groups and controls were different with respect to $\mathrm{BIC} \%, \mathrm{BV} \%$ and bone-implant interface strength in the study. Gotfredsen et al. also found that bone density and the mineralized bone-implant contact were higher at the static loaded sites than the unloaded sites in a series of animal experiments [50-52]. The different results may indicate bone tissue around implants can weaken or eliminate the detrimental effects of original loading in peri-implant bone within a short time, but the stress exceeding a certain threshold may cause the accumulation of bone damage and trigger bone loss. Thus, insertion torque or bone contention may be appropriately increased to enhance the primary implant stability, whereas the intensity of functional and non-functional load should be strictly controlled to avoid overload-induced bone resorption.

Our FE data may have clinical importance for implant design and loading management. We observed that the reduction in bone stress was not significant after BIC\% exceeding 50\%. Clinical studies show that BIC\% is commonly less than $80 \%$ for successful implantation [44]. Thereby, it appears safe for peri-implant bone to begin to withstand functional loads in clinic when BIC\% exceeds $50 \%$. In addition, FE results showed that the integrated region on the bone-implant interface could bear more load than the nonintegrated region. Previous studies indicate that the bioactive coating [40,41] and roughness [42] of implants could significantly influence cell differentiation, local factor production and, consequently, osseointegration and bone growth. Thus, if osseointegration can occur earlier in the low stress region than the high stress region by different surface modifications on implant interface, the risk of overload-induced bone loss may decrease. For our future studies, we will investigate how the external load is evenly transmitted to peri-implant bone and how the stress in marginal bone is decreased.

\section{Conclusion}

The load-bearing capacity of peri-implant bone is weak in the early period after implantation. The immediate loading significantly increases bone stress and intensifies nonuniform stress distribution when BIC\% is less than $50 \%$. In addition, bone stress can decrease as osseointegration proceeds, while the activity of bone remodeling and osseointegration is directly related to the stress magnitude level in the peri-implant bone. The favorable bone responses may be continually promoted when the peri-implant bone stress is maintained at a definite level.

This work was supported by the National Natural Science Foundation of China (10902010, 11120101001), National Science \& Technology Pillar Program of China (2012BAI22B02), and Research Fund for the Doctoral Program of Higher Education of China (20131102130004).

1 Pye AD, Lockhart DE, Dawson MP, Murray CA, Smith AJ. A review of dental implants and infection. J Hosp Infect, 2009, 72: 104-110

2 Araujo MG, Sukekava F, Wennstrom JL, Lindhe J. Ridge alterations following implant placement in fresh extraction sockets: an experimental study in the dog. J Clin Periodontol, 2005, 32: 645-652

3 Raghoebar GM, Schoen P, Meijer HJ, Stellingsma K, Vissink A. Early loading of endosseous implants in the augmented maxilla: a 1-year prospective study. Clin Oral Implants Res, 2003, 14: 697-702

4 Degidi M, Piattelli A. 7-year follow-up of 93 immediately loaded titanium dental implants. J Oral Implantol, 2005, 31: 25-31

5 Gapski R, Wang HL, Mascarenhas P, Lang NP. Critical review of 
immediate implant loading. Clin Oral Implants Res, 2003, 14: $515-527$

6 Tawil G. Peri-implant bone loss caused by occlusal overload: repair of the peri-implant defect following correction of the traumatic occlusion. A case report. Int J Oral Maxillofac Implants, 2008, 23: $153-157$

7 Quirynen M, Naert I, van Steenberghe D. Fixture design and overload influence marginal bone loss and fixture success in the Branemark system. Clin Oral Implants Res, 1992, 3: 104-111

8 Miyata T, Kobayashi Y, Araki H, Ohto T, Shin K. The influence of controlled occlusal overload on peri-implant tissue. Part 3: A histologic study in monkeys. Int J Oral Maxillofac Implants, 2000, 15: 425-431

9 Miyata T, Kobayashi Y, Araki H, Motomura Y, Shin K. The influence of controlled occlusal overload on peri-implant tissue: a histologic study in monkeys. Int J Oral Maxillofac Implants, 1998, 13: 677-683

10 Isidor F. Loss of osseointegration caused by occlusal load of oral implants. A clinical and radiographic study in monkeys. Clin Oral Implants Res, 1996, 7: 143-152

11 Naert I, Quirynen M, van Steenberghe D, Darius P. A study of 589 consecutive implants supporting complete fixed prostheses. Part II: Prosthetic aspects. J Prosthet Dent, 1992, 68: 949-956

12 Misch CE, Suzuki JB, Misch-Dietsh FM, Bidez MW. A positive correlation between occlusal trauma and peri-implant bone loss: literature support. Implant Dent, 2005, 14: 108-116

13 Vandamme K, Naert I, Geris L, Sloten JV, Puers R, Duyck J. Histodynamics of bone tissue formation around immediately loaded cylindrical implants in the rabbit. Clin Oral Implants Res, 2007, 18: $471-480$

14 Kim SH, Choi BH, Li J, Kim HS, Ko CY, Jeong SM, et al. Peri-implant bone reactions at delayed and immediately loaded implants: an experimental study. Oral Surg Oral Med Oral Pathol Oral Radiol Endod, 2008, 105: 144-148

15 Barbier L, Schepers E. Adaptive bone remodeling around oral implants under axial and nonaxial loading conditions in the dog mandible. Int J Oral Maxillofac Implants, 1997, 12: 215-223

16 De Smet E, Jaecques SV, Jansen JJ, Walboomers F, Vander Sloten J, Naert IE. Effect of constant strain rate, composed of varying amplitude and frequency, of early loading on peri-implant bone (re)modelling. J Clin Periodontol, 2007, 34: 618-624

17 Zhou YQ, Wang XH, Fan Y, Zhu Y, Tan WT, Mao Q. Predictive value of virological response on sustained virological response in hepatitis C patients (in Chinese). Zhonghua Gan Zang Bing Za Zhi, 2009, 17: 944-946

18 Yoon KH, Kim SG, Lee JH, Suh SW. 3D finite element analysis of changes in stress levels and distributions for an osseointegrated implant after vertical bone loss. Implant Dent, 2011, 20: 354-359

19 Pessoa RS, Muraru L, Junior EM, Vaz LG, Sloten JV, Duyck J, Jaecques SV. Influence of implant connection type on the biomechanical environment of immediately placed implants-CTbased nonlinear, three-dimensional finite element analysis. Clin Implant Dent Relat Res, 2010, 12: 219-234

20 Geng JP, Tan KB, Liu GR. Application of finite element analysis in implant dentistry: a review of the literature. J Prosthet Dent, 2001, 85: 585-598

21 Huang HL, Hsu JT, Fuh LJ, Tu MG, Ko CC, Shen YW. Bone stress and interfacial sliding analysis of implant designs on an immediately loaded maxillary implant: a non-linear finite element study. J Dent, 2008, 36: 409-417

22 Ding X, Liao SH, Zhu XH, Zhang XH, Zhang L. Effect of diameter and length on stress distribution of the alveolar crest around immediate loading implants. Clin Implant Dent Relat Res, 2009, 11: 279-287

23 Ihde S, Goldmann T, Himmlova L, Aleksic Z. The use of finite element analysis to model bone-implant contact with basal implants. Oral Surg Oral Med Oral Pathol Oral Radiol Endod, 2008, 106: $39-48$
24 Papavasiliou G, Kamposiora P, Bayne SC, Felton DA. 3D-FEA of osseointegration percentages and patterns on implant-bone interfacial stresses. J Dent, 1997, 25: 485-491

25 Yang J, Xiang HJ. A three-dimensional finite element study on the biomechanical behavior of an FGBM dental implant in surrounding bone. J Biomech, 2007, 40: 2377-2385

26 Chou HY, Jagodnik JJ, Muftu S. Predictions of bone remodeling around dental implant systems. J Biomech, 2008, 41: 1365-1373

27 Field C, Li Q, Li W, Thompson M, Swain M. Prediction of mandibular bone remodelling induced by fixed partial dentures. J Biomech, 2010, 43: 1771-1779

28 Tepper G, Haas R, Zechner W, Krach W, Watzek G. Threedimensional finite element analysis of implant stability in the atrophic posterior maxilla: a mathematical study of the sinus floor augmentation. Clin Oral Implants Res, 2002, 13: 657-665

29 Erkmen E, Simsek B, Yucel E, Kurt A. Comparison of different fixation methods following sagittal split ramus osteotomies using three-dimensional finite elements analysis. Part 1: advancement surgery-posterior loading. Int J Oral Maxillofac Surg, 2005, 34: $551-558$

30 Huang HM, Lee SY, Yeh CY, Lin CT. Resonance frequency assessment of dental implant stability with various bone qualities: a numerical approach. Clin Oral Implants Res, 2002, 13: 65-74

31 Van Oosterwyck H, Duyck J, Vander Sloten J, Van der Perre G, De Cooman M, Lievens S, Puers R, Naert I. The influence of bone mechanical properties and implant fixation upon bone loading around oral implants. Clin Oral Implants Res, 1998, 9: 407-418

32 Rancourt D, Shirazi-Adl A, Drouin G, Paiement G. Friction properties of the interface between porous-surfaced metals and tibial cancellous bone. J Biomed Mater Res, 1990, 24: 1503-1519

33 Frost HM. Perspectives: bone's mechanical usage windows. Bone Miner, 1992, 19: 257-271

34 Rubin CT, Lanyon LE. Regulation of bone mass by mechanical strain magnitude. Calcif Tissue Int, 1985, 37: 411-417

35 Turner $\mathrm{CH}$, Forwood MR, Rho JY, Yoshikawa T. Mechanical loading thresholds for lamellar and woven bone formation. J Bone Miner Res, 1994, 9: 87-97

36 Melsen B, Lang NP. Biological reactions of alveolar bone to orthodontic loading of oral implants. Clin Oral Implants Res, 2001, 12: $144-152$

37 Duyck J, Ronold HJ, Van Oosterwyck H, Naert I, Vander Sloten J, Ellingsen JE. The influence of static and dynamic loading on marginal bone reactions around osseointegrated implants: an animal experimental study. Clin Oral Implants Res, 2001, 12: 207-218

38 De Smet E, Jaecques SV, Wevers M, Jansen JA, Jacobs R, Sloten JV, Naert IE. Effect of controlled early implant loading on bone healing and bone mass in guinea pigs, as assessed by micro-CT and histology. Eur J Oral Sci, 2006, 114: 232-242

39 Gotfredsen K, Berglundh T, Lindhe J. Bone reactions at implants subjected to experimental peri-implantitis and static load-A study in the dog. J Clin Periodontol, 2002, 29: 144-151

40 Li Y, Li Q, Zhu S, Luo E, Li J, Feng G, Liao Y, Hu J. The effect of strontium-substituted hydroxyapatite coating on implant fixation in ovariectomized rats. Biomaterials, 2010, 31: 9006-9014

41 Sollazzo V, Pezzetti F, Scarano A, Piattelli A, Bignozzi CA, Massari L, Brunelli G, Carinci F. Zirconium oxide coating improves implant osseointegration in vivo. Dent Mater, 2008, 24: 357-361

42 Shalabi MM, Gortemaker A, Van't Hof MA, Jansen JA, Creugers NH. Implant surface roughness and bone healing: a systematic review. J Dental Res, 2006, 85: 496-500

43 Sedlin ED. A rheologic model for cortical bone. A study of the physical properties of human femoral samples. Acta Orthop Scand Suppl, 1965, Suppl 83: 1-77

44 Okumura N, Stegaroiu R, Kitamura E, Kurokawa K, Nomura S. Influence of maxillary cortical bone thickness, implant design and implant diameter on stress around implants: a three-dimensional finite element analysis. J Prosthodont Res, 2010, 54: 133-142 
45 Simsek B, Erkmen E, Yilmaz D, Eser A. Effects of different inter-implant distances on the stress distribution around endosseous implants in posterior mandible: a 3D finite element analysis. Med Eng Phys, 2006, 28: 199-213

46 Kitamura E, Stegaroiu R, Nomura S, Miyakawa O. Biomechanical aspects of marginal bone resorption around osseointegrated implants: considerations based on a three-dimensional finite element analysis. Clin Oral Implants Res, 2004, 15: 401-412

47 Bidez MW, Misch CE. Issues in bone mechanics related to oral implants. Implant Dent, 1992, 1: 289-294

48 Frost HM. A 2003 update of bone physiology and Wolff's Law for clinicians. Angle Orthod, 2004, 74: 3-15
49 Halldin A, Jimbo R, Johansson CB, Wennerberg A, Jacobsson M, Albrektsson T, Hansson S. The effect of static bone strain on implant stability and bone remodeling. Bone, 2011, 49: 783-789

50 Gotfredsen K, Berglundh T, Lindhe J. Bone reactions at implants subjected to experimental peri-implantitis and static load. A study in the dog. J Clin Periodontol, 2002, 29: 144-151

51 Gotfredsen K, Berglundh T, Lindhe J. Bone reactions adjacent to titanium implants subjected to static load. A study in the dog (I). Clin Oral Implants Res, 2001, 12: 1-8

52 Gotfredsen K, Berglundh T, Lindhe J. Bone reactions adjacent to titanium implants subjected to static load of different duration. A study in the dog (III). Clin Oral Implants Res, 2001, 12: 552-558

Open Access This article is distributed under the terms of the Creative Commons Attribution License which permits any use, distribution, and reproduction in any medium, provided the original author(s) and source are credited. 